\title{
Death Due To Complication of Ascariasis: A Case Report
}

\author{
Ostwal $\mathrm{K}^{1}$, Iravane $\mathrm{J}^{2}$, Damle $\mathrm{A}^{3}$ \\ ${ }^{1,2,3}$ Department of Microbiology, Government medical college Aurangabad, INDIA
}

\begin{abstract}
A 5 year old male child was admitted to emergency department with chief complains of pain in abdomen\&abdominal distension, vomiting, constipation since 4 days. Patient was febrile \&tachypnoeic. Abdominal distension \& rigidity was seen. X-ray \& Ultrasound both were inconclusive for the possible cause of intestinal obstruction.Patient underwent exploratory laparotomy with enterotomy for worm decompression. Nearly 400 worms were recovered.These worms were sent to microbiology laboratory and were identified as AscarislumbricoidesHowever the patient succumbed after 5 hours. The cause of respiratory distress \& cause of death remained unknown.
\end{abstract}

Keywords: Ascarislumbricoides, Death, Intestinal Obstruction

\section{Introduction:}

Ascarislumbricoides is one of the common intestinal nematodes affecting children. It can result ingastrointestinal impairment, malnutrition \& eventuallyimpairment in physical, intellectual, and cognitive development of children[1]. In severe cases may cause intestinal obstruction. It is an easily treatable cause of intestinal obstruction. If neglected, it may lead to death. So this cause needs to be addressed properly to avoid deaths due to poor sanitation.

\section{Case Report}

A 5 year old male child was admitted to emergency department with complaints of pain in abdomen ,abdominal distension, vomiting, constipation since 4 days, \&fever since 2 days . On examination patient was febrile \&tachypnoeic. Abdominal distension \& rigidity was seen.X-ray showedmultiple air fluid levels suggestive of intestinal obstruction.Ultrasonography showed evidence of dilated bowel loops containing ecogenic material with peristaltic movement, with no cause responsible for obstruction.

\section{Surgical Intervention}

Patient underwent exploratory laparotomy with enterotomy for worm decompression. Extensive worm balls occupying stomach, terminal ileum \&proximal large bowel were found. Part of terminal ileum was gangrenous and was resected followed by end to end anastomosis. Nearly 400 worms were removed. These worms were also sent to Microbiology Laboratory.

3.1 Patient had respiratory distress post-operatively. In spite of all supportive treatment,the patient succumbed after 5 hours.

\section{Microbiological work up}

The worms removed post operatively were sent to microbiology Laboratory for identification. On gross examination there were some worms of size $15-20 \mathrm{~cm}$ X 2-4 mm and some of size $25-30 \mathrm{~cm} \mathrm{X} \mathrm{3-5} \mathrm{mm.} \mathrm{On} \mathrm{the}$ basis of size and morphology the smaller ones with curved round ends were identified as male Ascarislumbricoides and longer with straight ends as female Ascarislumbricoides. We crushed the middle part of few female adult worms and found heaps of uncorticated, fertilized eggs of size $60 \mu \mathrm{m} \times 40 \mu \mathrm{m}$ of Ascarislumbricoides

\section{Discussion:}

Roundworm related intestinal obstruction is more common in children because of the smaller diameter of the lumen of the bowel[2]. Obstruction due to Ascariasis commonly occurs at the terminal ileum. Usually Ultrasonography indicates the presence of round worms[2] but was not seen in our case. Death due to ascaris is very rare. Among intestinal obstruction due to round worms 35.5\% deaths were reported by Louw[3]. Death due to Ascaris has been reported to be caused by wandering worms causing airway blockage[4]. However parents of deceased child refused for clinical post mortem so the cause of respiratory distress \& cause of death in our case remained unknown.

5.1In our case it was found that none of the diagnostic procedures were able to conclusively give cause of intestinal obstruction.Eventually the worms were identified by microbiologist. The eggs found inside the body of female worm were all uncorticated, fertilized eggs. The process of cortication occurs at a later stage. The 
mammilated layer also called uterine or proteinatious layer is contributed by uterine wall [4]. Therefore the eggs that we have seen are ones which have yet to obtain the said layer. That is the reason, we have used uncorticated instead of de corticated egg.

\section{Conclusion}

We are reporting death due to complication of Ascariasis which is quite rare.

\section{Journal papers:}

\section{References}

[1]. Bethony J Brooker S Albonico M, et al. Soil-transmitted helminth infections: ascariasis, trichuriasis, and hookworm. Lancet 2006;367:

[2]. Mishra PK AgrawalA Joshi M Sanghvi B Shah H Parelkar SV. Intestinal obstruction in children due to Ascariasis: A tertiary health centre experience. Afr J PaediatrSurg 2008;5:65-70

[3] Louw JH. Abdominal complications of Ascarislumbricoides infestation in children. Br J Surg 1966;53:510-21.

[4] G.D Schmidt L.S RobertsFoundations of Parasitology $2^{\text {nd }}$ edition p.483-92 Mosby Missouri USA 1981 